University of South Carolina

Scholar Commons

4-2012

\title{
Acquisition of initial mental graphemic representations by children at risk for literacy development
}

\author{
Kenn Apel \\ University of South Carolina - Columbia, kennapel@mailbox.sc.edu \\ Shurita Thomas-Tate \\ Elizabeth B. Wilson-Fowler \\ Danielle Brimo
}

Follow this and additional works at: https://scholarcommons.sc.edu/

sph_communication_sciences_disorders_facpub

Part of the Communication Sciences and Disorders Commons, and the Public Health Commons

\section{Publication Info}

Published in Applied Psycholinguistics, Volume 33, Issue 2, 2012, pages 365-391.

Apel, K., Thomas-Tate, S, Wilson-Fowler, E. B., \& Brimo, D. (2012). Acquisition of initial mental graphemic representations by children at risk for literacy development. Applied Psycholinguistics, 33(2), 365-391. DOI: $10.1017 /$ S0142716411000403

(C) Applied Psycholinguistics, 2012, Cambridge University Press

This Article is brought to you by the Communication Sciences and Disorders at Scholar Commons. It has been accepted for inclusion in Faculty Publications by an authorized administrator of Scholar Commons. For more information, please contact digres@mailbox.sc.edu. 


\title{
Acquisition of initial mental graphemic representations by children at risk for literacy development
}

\author{
KENN APEL, SHURITA THOMAS-TATE, ELIZABETH B. \\ WILSON-FOWLER, and DANIELLE BRIMO \\ Florida State University
}

Received: September 3, 2009 Accepted for publication: June 7, 2010

\section{ADDRESS FOR CORRESPONDENCE}

Kenn Apel, School of Communication Science and Disorders, Florida State University, 127 Honors

Way, Tallahassee, FL 32306. E-mail: kenn.apel@cci.fsu.edu

\begin{abstract}
We examined the acquisition of initial mental graphemic representations (MGRs) by 46 kindergarten children (mean age $=5$ years, 9 months) at risk for literacy development because of low socioeconomic status. Using a storybook context, we exposed children to novel nonwords that varied in their phonotactic and orthotactic probabilities and then assessed the children's development of initial MGRs through spelling and reading recognition tasks. The children developed some initial MGRs but less than past reports of children from middle socioeconomic status backgrounds. Children with more advanced word recognition abilities developed more initial MGRs than their peers with less advanced word recognition skills. Like previous reports, the words' linguistic properties affected initial MGR acquisition and MGR acquisition ability predicted reading and spelling achievement above other known predictors. The results speak to the importance of increasing the print and orthographic knowledge of children at-risk for adequate literacy development.
\end{abstract}

The greatest obstacle to success in literacy development for children in the early elementary grades is word recognition (McCardle, Scarborough, \& Catts, 2001). Fluent word recognition is dependent on adequate storage and retrieval of the mental representations of written words, or mental graphemic representations ${ }^{1}$ (MGRs; Apel \& Masterson, 2001). When reading, individuals who directly access their stored MGRs tend to read fluently and with meaning. Writing can be automatic and fluent, with little forethought about words' spellings, when wellinstantiated MGRs are retrieved. With poorly developed MGRs, individuals must take an indirect, decoding route to reading, sounding out words to access meaning, often leading to less fluent reading. Similarly, with insufficient MGRs, spellers must segment a spoken word into its individual phonemes, link those phonemes to their corresponding grapheme(s), and then write them down, a less fluent process in writing. Thus, MGRs play a significant role in fluent reading and writing (e.g., 
Cunningham, 2006; Klauda \& Guthrie, 2008; Share, 2004). In this investigation, we examined the acquisition of initial MGRs by young children known to be at risk for literacy development, children with low socioeconomic status (SES) backgrounds, most of whom were African American. The study was motivated by past research demonstrating that young beginning readers' ability to quickly and relatively implicitly acquire initial MGRs is related to and predicts their reading and spelling skills above other known foundational skills (e.g., phonemic awareness, letter knowledge).

\section{INITIAL MGR ACQUISITION}

Although some researchers have examined initial MGR acquisition in beginning readers (e.g., kindergarten and first grade children) through explicit teaching situations (Ehri \& Saltmarsh, 1995; Ehri \& Wilce, 1985, 1987a, 1987b), more recent studies have focused on MGR learning in implicit contexts (Apel, 2010; Apel, Wolter, \& Masterson, 2006; Wolter \& Apel, 2010). Using an experimental procedure to examine MGR acquisition, Apel and colleagues found that preschool and kindergarten children quickly acquired initial MGRs after minimal exposure to novel written nonwords within adult-led storybook reading situations. In these studies, children were read a series of short stories; each story contained one novel nonword. During the storybook reading, the novel nonwords were seen and heard four times. Following each story, the children were required to spell the novel target nonword and identify it from an array of three to four possible word choices. Their results suggested that children rapidly acquired some initial MGR information and that this ability to develop initial MGRs was related to and accounted for unique variance on measures of their reading and spelling abilities. The studies by Apel and associates, as well as the work of Evans, Williamson, and Pursoo (2008), augment findings from more explicit written word teaching studies (e.g., Ehri \& Saltmarsh, 1995; Ehri \& Wilce, 1985, 1987a, 1987b; Reitsma, 1983) by demonstrating early MGR learning occurs during relatively implicit learning situations that mirror common, daily adult-child situations (Justice, 2002).

Numerous studies have demonstrated that young children can acquire initial MGRs relatively quickly; fewer have examined the influence of words' linguistic regularities on that learning (e.g., Apel, 2010; Apel et al., 2006; Levy, Gong, Hessels, Evans, \& Jared, 2006; Wolter \& Apel, 2010; Wright \& Ehri, 2007). Wright and Ehri (2007) explicitly taught children novel words that contained consonant or vowel doublets in legal or illegal positions (e.g., rrag, for rag, contains an illegal doublet). The researchers then determined the number of trials required to learn the words and the children's retention of the information (2 to 3 days postinitial testing). Less learning trials were required and retention was better for words that did not violate doublet rules. In Apel and colleagues' studies (e.g., Apel et al., 2006), the target nonwords varied in their phonotactic (frequency with which words' phonemes and biphones occur in the English lexicon) and orthotactic (frequency with which words' graphemes and bigraphs occur in the English lexicon) probabilities. Across several studies, kindergarten children demonstrated sensitivity to the words' linguistic probabilities. In general, these children acquired more initial MGRs representing words with high orthotactic probability, as 
evidenced in their ability to spell the target nonwords accurately. One of the studies found an interaction effect; preschool children developed more MGRs for words representing high orthotactic and high phonotactic probabilities (Apel et al., 2006). Another investigation found that kindergarten children also recognized more target nonwords representing low phonotactic probability (Wolter \& Apel, 2010).

As a whole, these investigations suggest that words' orthographic regularities typically influence initial MGR learning and that their phonological regularities, at times, also may affect the word learning process. It should be noted that phonotactic and orthotactic probabilities are closely associated with measures of phonological and orthographic neighborhood density (e.g., Storkel, 2009). Phonological and orthographic neighborhood density are lexical characterizations of the number of words that share all but one sound or letter, respectively. Thus, the results from the Apel and colleague studies may have been due to the words' neighborhood densities.

Storkel's spoken word learning theory, which is based on words' statistical regularities (Storkel, 2009; Storkel, Armbruster, \& Hogan, 2006), can be used to explain the influence of words' statistical probabilities on initial MGR acquisition. According to Storkel (2009), new spoken words that contain less frequent sound combinations (i.e., low phonotactic probability) trigger learners to begin the word learning process because the words represent forms that are novel compared to previously stored representations. In addition, new words that are highly similar to previously stored words (i.e., high density words) are stored more efficiently initially because of the high degree of shared phonological-lexical characteristics with stored representations. Apel (2010) extended Storkel's (2009) theory to initial written word learning, suggesting that the positive effect of high orthotactic probability on initial MGR learning was akin to Storkel's (2009) notion of the influence of high neighborhood density on word learning.

Storkel's word-learning theory fits well with Gershkoff-Stowe and Hahn's (2007) claim that vocabulary size influences word learning. With greater vocabulary size, the likelihood of larger neighborhoods with which to relate new words increases. Although Gershkoff-Stowe and Hahn's (2007) premise has not been applied to written vocabulary, a similar claim could be made; when an individual has a broad base of stored MGRs, the shared linguistic regularities of the stored MGRs with MGRs being acquired may facilitate the word-learning process.

Although there is a growing research base regarding initial MGR acquisition in explicit and implicit learning situations, little is known about initial MGR acquisition in at-risk populations. Most researchers have studied initial MGR acquisition in children who were primarily Caucasian and from middle to high SES backgrounds (e.g., Apel, 2010; Apel et al., 2006; Ehri \& Saltmarsh, 1995; Ehri \& Wilce, 1985, 1987a, 1987b; Reitsma, 1983; Wolter \& Apel, 2010). As an exception, Wright and Ehri (2007) investigated initial MGR acquisition using an explicit teaching task in children who were primarily African American and from low SES backgrounds. Their participants demonstrated some initial MGR development as a response to their training. What remains to be determined, however, is whether at-risk groups of children, such as children from low SES backgrounds, acquire initial MGRs in less explicit, naturally occurring situations, such as in a storybook reading context. Given the extant literature that suggests 
Apel et al.: Acquisition of initial MGRs

children at risk for literacy development struggle to develop specific literacy and literacy-related skills, it may be that their ability to implicitly acquire initial MGRs also may be at risk.

\section{CHILDREN AT RISK FOR ADEQUATE LITERACY DEVELOPMENT}

Children from low SES backgrounds and African American children typically perform poorly compared to their middle SES and Caucasian counterparts on measures of reading and writing. For example, according to the National Assessment of Educational Progress (2007), 50\% of fourth grade children from low-income backgrounds, as determined by eligibility for free and reduced price lunch (FARL), scored below a basic level of reading on a nationally administered reading test, compared to $21 \%$ of children who did not qualify for FARL. Similarly, $54 \%$ of African American fourth graders scored below the basic level of reading compared to $22 \%$ of Caucasian fourth graders. African Americans are overrepresented in the low SES population and thus are particularly at risk for literacy difficulties (Craig \& Washington, 2004; Snow, Burns, \& Griffin, 1999; United States Census Bureau, 2008; Washington, 2001). The 2007 National Assessment of Educational Progress reported that $60 \%$ of low-income, African American fourth graders were reading below the basic level of reading compared to $38 \%$ of Caucasian, lowincome students. Thus, African American children and children from low SES backgrounds are considered to be at risk for developing poor literacy skills.

It may be that poor literacy outcomes for children from low SES backgrounds and African American children arise early in development as a result of differences in early speech, language, and literacy skills and experiences, compared to nonat-risk groups. For example, Duncan and Seymour (2000) reported that preschool and kindergarten age children from low SES backgrounds scored significantly lower on measures of letter knowledge and phonemic awareness than their middle SES counterparts. Molfese et al. (2006) found that over 50\% of their low SES preschool children learned little to no new letter knowledge following an academic year of instruction that included specific focus on letter names. Of importance, though, Molfese and colleagues noted great diversity in the children's abilities; not all children from low SES backgrounds presented with the same lower level of letter knowledge. Finally, numerous studies have reported that African American students from low-income backgrounds perform poorly on standardized measures of vocabulary compared to their middle income and Caucasian peers (PattonTerry, Connor, Thomas-Tate, \& Love, in press; Qi, Kaiser, Milan, \& Hancock, 2006; Thomas-Tate, Washington, Craig, \& Packard, 2006). Low-income status, regardless of race or ethnicity, appears to contribute to poorer performance on standardized measures of vocabulary.

The less robust performance of at-risk groups on measures of vocabulary, phonemic awareness, and letter knowledge may be due to decreased or restricted exposure to language, print, and reading experiences before they reach school. For example, children in at-risk groups tend to have less parental language input (e.g., Hoff, 2003; Pan, Rowe, Singer, \& Snow, 2005), including less exposure to a broad vocabulary base (e.g., Hart \& Risley, 1995), than Caucasian children and children from middle SES backgrounds. The restricted input not only may affect exposure 
to and practice with sound play and letter-learning tasks, it also may result in a smaller or limited vocabulary.

As mentioned earlier, vocabulary size impacts word learning in a cascading or cyclical fashion (Marchman \& Fernald, 2008). For example, children with large spoken word vocabularies learn more information about novel spoken words during first exposures than children with smaller vocabularies (Gershkoff-Stowe $\&$ Hahn, 2007). This phenomenon likely occurs because larger vocabularies are the by-product of consistent and frequent opportunities to learn words, leading to greater automaticity in the word learning process (Gershkoff-Stowe \& Hahn, 2007). In addition, information about new words can be more easily stored in and retrieved from memory when that information shares lexical and sublexical characteristics of previously learned vocabulary. Shared linguistic characteristics enable better integration of the new information with known information (Storkel, 2009) and better retrieval of that new information because of mutual activation of related forms (Gershkoff-Stowe \& Hahn, 2007). Finally, with greater vocabulary knowledge, individuals are more apt to extract the linguistic statistical regularities of words (e.g., Munson, Kurtz, \& Windsor, 2005) and then use that statistical information to enhance further word learning (e.g., Apel et al., 2006; Storkel, 2001; 2009; Storkel \& Rogers, 2000). Although it has not been systematically investigated, it is likely that children with larger written word vocabularies, or larger MGR lexicons, may learn more MGRs than their counterparts with fewer stored MGRs. Thus, the reported fewer exposures to written words experienced by children from low SES backgrounds may have a cascading effect on initial MGR acquisition; less exposure leads to fewer stored MGRs from which to learn new representations.

Researchers also have reported that African American children and children from low SES backgrounds are less likely to be engaged in adult-led storybook reading during the preschool years than their Caucasian, middle SES peers (e.g., Washington, 2001). These at-risk groups also receive lower levels of print-related experiences (Justice, Kaderavek, Fan, Sofka, \& Hunt, 2009; Justice, Pullen, \& Pence, 2008); the experiences they do gain with print often come from environmental print rather than book print (Craig \& Washington, 2004; Heath, 1983; Roberts, Jurgens, Burchinal, 2005; Vernon-Feagans, Hammer, Miccio, \& Manlove, 2001). With less exposure to print in books and early reading experiences, these children may not develop an adequate or early appreciation for the purpose and conventions of print and knowledge that the specific orthographic forms of words are consistent. Finally, these children may not gain many experiences for how adults monitor young children's comprehension of texts or knowledge of its conventions (e.g., how to answer questions about what has been read; Anderson-Yockel \& Haynes, 1994; Craig, Connor, \& Washington, 2003), a procedure that mirrors academic situations.

Children from middle SES homes are frequently engaged in situations that encourage implicit literacy learning (Justice, 2002); children from low SES backgrounds are engaged less (Bus, van IJzendoorn, \& Pelligrini, 1995; Taylor \& Dorsey-Gaines, 1988; Teale, 1986). Fewer experiences with these implicit learning situations may lead to less robust written word learning. To date, two studies have specifically investigated the early spoken word learning abilities of children 
considered to be at risk within more implicit learning contexts; results from both studies suggested these children do not differ from their middle SES peers in their initial spoken word learning abilities (Horton-Ikard \& Weismer, 2007; Johnson, 2001). However, there have been no investigations of the initial written word learning abilities of this child population. It may be that, unlike initial spoken word learning, the documented reduced language, reading, and print exposures experienced by children from low SES backgrounds and African American children impact initial MGR acquisition.

\section{PURPOSE OF STUDY}

In this descriptive study, we sought to understand initial MGR acquisition and its relation to literacy skills for kindergarten children considered to be at risk for literacy development: primarily children from low SES backgrounds, most of whom were African American. We hypothesized that children from low SES backgrounds would perform poorly on measures of initial MGR acquisition because of their documented fewer experiences with print-related and reading activities (e.g., Craig \& Washington, 2004; Heath, 1983; Roberts et al. 2005; Vernon-Feagans et al., 2001). However, we expected that the linguistic properties of the words would impact the abilities of the at-risk children to acquire initial MGRs in a manner similar to past reports for children not at risk for literacy development and that initial MGR learning ability would predict unique variance on reading and spelling measures. These latter hypotheses were based on previous investigations that demonstrated that the written word learning skills of younger children and other children known to be at risk for literacy development (i.e., children with language impairment; Wolter \& Apel, 2010) were influenced by words' statistical regularities and were predictive of or related to reading and spelling ability (e.g., Apel et al., 2006; Wolter \& Apel, 2010). Finally, we were interested in determining whether subgroups of children who varied in their written word recognition abilities, a proxy for the size of their MGR lexicon, differed in initial MGR acquisition skills. Extending the work of Gershkoff-Stowe and Hahn (2007), we hypothesized that children with greater written word recognition skills would demonstrate greater initial MGR learning abilities than peers with less advanced word recognition skills.

Specifically, the following research questions were asked:

1. Within an experimental MGR learning procedure, do children from at-risk populations acquire initial MGRs?

2. Is initial MGR acquisition by children from at-risk populations influenced by the phonotactic and orthotactic probabilities of the novel nonwords?

3. Do children from at-risk populations who vary in their written word recognition skills differ in their ability to acquire initial MGRs and, if so, is that acquisition influenced by the phonotactic and orthotactic probabilities of the novel nonwords?

4. Does the performance on an experimental MGR learning procedure by children from at-risk populations account for significant, unique variance on reading and spelling measures above that explained by other known predictors of literacy development (e.g., receptive vocabulary, phonemic awareness, letter knowledge)? 


\section{METHOD}

\section{Participants}

Kindergarten children were recruited from two urban elementary schools located in a southeastern state. Forty-six children were included in the study, based on signed parental consent forms consistent with university institutional review board requirements. Of these children, $23(50 \%)$ were male, $33(72 \%)$ were African American, $10(22 \%)$ were White, and $3(6 \%)$ were either multiracial or listed as "other ethnicity." The children ranged in age from 5 years, 3 months $(5 ; 3)$ to $7 ; 0$, with a mean age of $5 ; 9$. Twenty-nine of the students were enrolled in a school in which at least $65 \%$ of the children qualified for FARL status; the remaining 17 students were enrolled in a school in which at least $85 \%$ of the children qualified for FARL. Using these percentages as indices of family income, the participants were considered to be at risk for literacy development because of their low-income backgrounds. According to teacher report, all participants had negative histories for speech, language, motoric, sensory, or intellectual deficits. In addition, all children obtained a standard score of 85 or greater $(M=98.83, S D=$ 10.24) on the Matrices subtest of the Kaufman Brief Intelligence Test-Second Edition (Kaufman \& Kaufman, 2004) confirming nonverbal cognitive skills within typical limits. Consistent with past investigations, the children were considered to be beginning readers (e.g., Apel, 2010; Ehri \& Saltmarsh, 1995; Ehri \& Wilce, 1985).

Although no formal measure of dialect use was collected, all of the African American participants were judged to be speakers of African American English (AAE) by trained speech-language pathologists (either the third or fourth author). Oetting and McDonald (2002) demonstrated that listener judgment could be an effective method in determining dialect use. Furthermore, all of the participants in this study attended schools where AAE was the primary language of the school and/or community. Students attending these schools are likely to speak the language variation of their school/community (Terry, Connor, Thomas-Tate, \& Love, 2010).

\section{Stimuli}

The stimuli for the experimental MGR learning procedure were those used previously by Apel and colleagues (Apel, 2010; Apel et al. 2006; Wolter \& Apel, 2010). The 12 nonword stimuli that varied in their phonotactic and orthotactic probabilities were first developed by Jusczyk, Luce, and Charles-Luce (1994). Half of the words represented words with high phonotactic probability and half represented words of low phonotactic probability. Similarly, half of the words represented high orthotactic probability and half represented words with low orthotactic probability. Thus, three nonwords represented each of the following four conditions: high phonotactic and high orthotactic probabilities, high phonotactic and low orthotactic probabilities, low phonotactic and high orthotactic probabilities, and low phonotactic and low orthotactic probabilities (see Table 1). High orthotactic probability nonwords were roughly 1.7 times more frequent in their statistical regularities than low orthotactic probability nonwords; high phonotactic 
Apel et al.: Acquisition of initial MGRs

Table 1. Nonword stimuli varying in phonotactic and orthotactic probability

\begin{tabular}{ccl}
\hline \hline Nonword Spelling & Pronunciation & Phonotactic/Orthotactic Condition \\
\hline hess & $/ \mathrm{h} \varepsilon \mathrm{s} /$ & High phonotactic/high orthotactic \\
chan & $/ \mathrm{f} æ \mathrm{l} /$ & High phonotactic/high orthotactic \\
sime & $/ \mathrm{saIm} /$ & High phonotactic/high orthotactic \\
knal & $/ \mathrm{næl} /$ & High phonotactic/low orthotactic \\
sush & $/ \mathrm{s} \Lambda \mathrm{c} /$ & High phonotactic/low orthotactic \\
cerz & $/ / \mathrm{s}^{\circ} \mathrm{z} /$ & High phonotactic/low orthotactic \\
chab & $/ \mathrm{f} \mathrm{sb} /$ & Low phonotactic/high orthotactic \\
thug & $/ \mathrm{d} \Lambda \mathrm{g} /$ & Low phonotactic/high orthotactic \\
gove & $/ \mathrm{guv} /$ & Low phonotactic/high orthotactic \\
zush & $/ \mathrm{zu} /$ & Low phonotactic/low orthotactic \\
gouz & $/ \mathrm{gauz} /$ & Low phonotactic/low orthotactic \\
chuz & $/ \mathrm{t} \Lambda \mathrm{z} /$ & Low phonotactic/low orthotactic \\
\hline \hline
\end{tabular}

probability nonwords were approximately three times more frequent in statistical regularities than low phonotactic probability nonwords. In addition, the majority of sound-spelling regularities in the nonwords were transparent (see data from http://spell.psychology.wustl.edu/RelSoundLetMono/results.html). Of the 36 total sound-spelling correspondences across the 12 nonwords, six letters could be expected to vary depending on linguistic context (e.g., coda affecting the vowel spelling; Kessler \& Treiman, 2001). These six letters were evenly distributed across nonwords representing high and low orthotactic probabilities, suggesting differences in regular sound-spelling correspondences would not affect outcomes. As noted in Apel (2010), the stimuli were constructed to vary by phonotactic and orthotactic probability, but were strongly correlated with neighborhood densities. Thus, the words could be characterized as representing high probability/density versus low probability/density.

\section{Procedures}

All participants were administered the experimental procedure first. Subsequently, the remaining tasks were conducted in randomized order. Administration was conducted over two sessions, with no more than 1 week elapsing between sessions. Each session lasted approximately $45 \mathrm{~min}$. All tasks were administered by the third and fourth authors or undergraduate or graduate students trained by these authors in all procedures used in the study.

Experimental MGR learning procedure. Using the same experimental procedure followed in Apel (2010) and Wolter and Apel (2010), the participants were exposed to the novel words using a simulated, shared storybook reading activity. The stories were presented via a PowerPoint $\subseteq$ presentation on a Toshiba Tecra A5S116 laptop. Each story contained four slides with the novel nonword stimuli 
embedded in each slide of the story (see Appendix A for sample story). The participants were told they would "learn about a Martian named Jak and the objects he used in outer space." Each novel nonword was presented four times, with one instance per slide (e.g., "This is about Jak's sime. A sime is smooth. Jak swings a sime. A sime is on the ground."). A digitized audio presentation of a female reading the story using Mainstream American English accompanied the slide presentation. The novel nonword was stressed through a natural increase in volume and frequency pitch. For each slide, the character Jak was shown with a novel object that was a nondescript drawing of an object that had been previously determined as unidentifiable by adults (Apel et al., 2006). Each slide also contained the written version of the sentence read for the slide. The sentences were written in 32 point Arial with the exception of the novel nonwords that were highlighted in 36 point bold Arial in purple. The PowerPoint slides automatically transitioned to the next slide every $15 \mathrm{~s}$. Initially, all participants were administered a practice novel nonword story during which the examiner explained the task expectations and made corrections if the child did not understand the instructions. The presentation order for the 12 stories was counterbalanced across participants.

After each story presentation, the participants were required to perform two tasks. First, they completed the production task. For this task, they were asked to spell the novel nonword given a picture stimulus on a PowerPoint slide and digitally recorded audio direction (i.e.,"Write what this thing is called."). Second, the participants completed the recognition task. In this task, they were required to point to the target written nonword from an array of four written nonwords on a PowerPoint slide. The array of words included the target nonword spelling (e.g., "hess"), a foil that varied minimally in spelling (alteration of one letter representing a change in the manner or voice of a phoneme, such as "ness" for "hess"), a foil that was maximally different in spelling (i.e., changes in two or more graphemes that were not cognates, such as "peff" for "hess"), and a real word (e.g., "you"). For both tasks, the participants were encouraged to guess and were given as much time as they needed to complete the task.

Responses for the production task were scored two ways. First, as in past investigations (e.g., Apel, 2010; Apel et al., 2006), the 12 spellings were scored as correct or incorrect (complete scoring). Letter reversals that did not result in a letter change (e.g., backward "c") or that were differentiated in the child's handwriting (e.g., "z" written backward that was differentiated from an "s" by straight vs. curved lines) were scored as correct responses. Whole-word accuracy on the production task was chosen to reduce the probability that the children were responding using their phonological recoding abilities. According to data compiled by Treiman (1993), first-grade children would be expected to accurately spell 11 of the nonwords using phonological recoding less than $20 \%$ of the time. For one word, "chan," first-grade children could be expected to spell the word correctly $42 \%$ of the time. Thus, as a whole, the likelihood that accuracy on the production task was due to phonological recoding was considered minimal.

The responses on the production task also were scored using the modified scoring procedure (partial scoring) described in Wolter and Apel (2010). In that study, there was a floor effect on the production task for the children with language impairment; many did not spell one word correctly. Thus, Wolter and Apel (2010) 
used a partial scoring procedure that credited children with a correct response when the spelling was completely correct or contained two of three correct letters/digraphs in the correct order. For digraphs (e.g., th, ss), a correct spelling was attributed to a child if s/he only wrote one of the two expected letters (e.g., $\mathrm{t}$ for th). In addition, the spelling could include up to two intervening incorrect letters between correct letters (e.g., chien for chan). The modified scoring procedure permitted documentation of partial MGR development and a greater range of performances. For the recognition task, responses were scored as correct or incorrect.

Additional tasks. Three skills previously identified in the literature as influencing early literacy ability were assessed: receptive vocabulary, phonemic awareness, and letter knowledge (e.g., Adams, 1990; Lonigan, Burgess, \& Anthony, 2000; Scarborough, 2002). Receptive vocabulary was measured using either the Peabody Picture Vocabulary Test-Fourth Edition (Dunn \& Dunn, 2007) or the Peabody Picture Vocabulary Test-Third Edition (Dunn \& Dunn, 1997). The phoneme segmentation and phoneme blending subtests of the Phonological Awareness Test (Robertson \& Salter, 1997) and a modified version of the Rosner's Auditory Analysis Test (RAAT; Rosner \& Simon, 1971) were used to measure phonemic awareness abilities. The three tasks were significantly associated (blending and segmenting, $r=.61, p<.001$; blending and RAAT, $r=.38, p=.009$; segmenting and RAAT, $r=.39, p=.007)$; thus, the raw scores were summed to form a phonemic awareness composite score. Finally, the letter identification subtest of the Woodcock Reading Mastery Test-Revised (WRMT-R; Woodcock, 1998) served as a measure of letter knowledge. The three sets of scores (receptive vocabulary score, phonemic awareness composite score, and letter identification score), along with scores on the Kaufman Brief Intelligence Test-Second Edition (Kaufman \& Kaufman, 2004), were subsequently examined for their relation to reading and writing compared to performance on the experimental MGR learning procedure.

The word attack and word identification subtests of the WRMT-R were used as early measures of reading ability. The raw scores on these two subtests were combined to form a reading composite score. Spelling ability was assessed using the following 10-item, spelling dictation task used by Wolter and Apel (2010): "fan," "pet," "dig," "mop," "rope," "wait," "chunk," "sled," "stick," and "shine." In an effort to capture the variability present in the children's spellings, Wolter and Apel's 8-point rating scale was used to score the participants' spellings (for the rating system, see Wolter \& Apel, 2010). Interscorer agreement was calculated on $12(21 \%)$ of participants' responses to the fast-mapping and spelling tasks. Agreement was calculated at $100 \%$ for both experimental MGR-learning tasks and $91 \%$ for the spelling dictation task.

\section{RESULTS}

Mean standard scores on the reading, letter identification, receptive vocabulary, and nonverbal cognition measures were within typical limits $(M=97-106)$ for kindergarten children according to national norms. On average, the children correctly responded to $40 \%$ of the phonemic awareness items $(M=16$ out of 40$)$. 
Table 2. Mean (standard deviation) group and subgroup performances on MGR acquisition and literacy measures

\begin{tabular}{lccc}
\hline \hline & $\begin{array}{c}\text { Total Group } \\
(N=46)\end{array}$ & $\begin{array}{c}\text { Group 1 } \\
(N=25)\end{array}$ & $\begin{array}{c}\text { Group 2 } \\
(N=21)\end{array}$ \\
\hline MGR acquisition measures & & & \\
$\quad$ Production task (complete scoring) & $0.78(1.76)$ & $0.24(0.72)$ & $1.43(2.36)$ \\
$\quad$ Production task (partial scoring) & $2.30(3.35)$ & $1.20(2.0)$ & $3.62(4.14)$ \\
$\quad$ Recognition task & $6.10(3.43)$ & $5.04(3.03)$ & $7.29(3.54)$ \\
Literacy measures & & & \\
$\quad$ PPVT-III, IV & $97.26(13.64)$ & $95.84(12.50)$ & $98.95(15.02)$ \\
Letter identification & $106.72(8.63)$ & $105.48(9.57)$ & $108.19(7.31)$ \\
$\quad$ Phonemic awareness composite & $15.61(8.86)$ & $12.56(6.43)$ & $19.24(10.07)$ \\
$\quad$ Reading composite & $10.41(18.23)$ & $3.36(5.40)$ & $18.81(24.00)$ \\
$\quad$ Spelling & $36.43(19.37)$ & $28.84(17.36)$ & $45.48(18.03)$ \\
$\quad$ KBIT-II & $98.83(10.24)$ & $98.08(9.53)$ & $99.71(11.20)$ \\
\hline \hline
\end{tabular}

Note: MGR, mental graphemic representations; Group 1, less advanced beginning readers; Group 2, more advanced beginning readers; PPVT-III, IV, Peabody Picture Vocabulary Test, 3rd or 4th edition; KBIT-II, Kaufman Brief Intelligence Test, 2nd Edition (matrices subtest). Mean raw scores are reported for all measures except for PPVT, Letter identification, and KBIT, for which mean standard scores are reported.

The group's mean spelling score (36 out of 80) suggested that the children typically spelled a word with two correct or phonemically similar letters or digraphs, with one of those letters being the initial letter of the word. See means and standard deviations for all measures in Table 2.

The Cronbach alpha was calculated across statistical regularity conditions (e.g., high phonotactic-high orthotactic probability) to provide an estimate of the reliability of the two MGR-learning tasks. Internal consistency reliability was calculated for the complete and partial scoring procedures for the production task and for the recognition task. All alphas were acceptable: production task (complete scoring), $\alpha=0.89$; production task (partial scoring), $\alpha=0.93$; recognition task, $\alpha=$ 0.82 .

\section{Initial MGR learning ability}

The results of the production and recognition tasks were examined to determine whether the children had acquired initial MGRs of the written nonwords. Using the complete scoring procedure for the production task, 24\% (11) of the participants spelled at least 1 of the 12 novel nonwords correctly $(M=0.78, S D=1.76)$. With the partial scoring procedure, $48 \%$ (22) of the children were credited with at least one correct spelling of a nonword $(M=2.30, S D=3.35)$. On the recognition task, $63 \%$ (29) of the children correctly identified more than 4 of the 12 target nonwords (above chance level; $M=6.10, S D=3.43$ ). The findings from the production and recognition tasks suggested that approximately two-thirds of the participants acquired some initial MGRs after minimal exposure to the target nonwords. 
Apel et al.: Acquisition of initial MGRs

\section{Influences of linguistic statistical regularities on initial MGR learning}

The participants' performances on the production and recognition tasks were examined to determine the influence of the target nonwords' linguistic regularities on their ability to acquire initial MGRs. On the production task, 76\% (35) of the children did not spell at least one word correctly; the mean number of words spelled completely correctly was low $(M=0.78, S D=1.76)$, suggesting a likely floor effect. Thus, results based on the partial scoring system were used to examine the effect of words' statistical probabilities on the production task. Consistent with past word-learning investigations (e.g., Apel, 2010; Gray, 2005, 2006; Wolter \& Apel, 2010), two, $2 \times 2$ repeated measures analysis of variance (ANOVA), with the within-subject variables of phonotactic probability (high vs. low) and orthotactic probability (high vs. low), were conducted for the production and recognition tasks, using a Bonferroni correction, with alpha level set at 0.025 , to correct for possible Type 1 errors.

On the production task, there was a significant main effect for orthotactic probability $\left(F=5.68, p=.021, \eta^{2}=0.11\right)$. More nonwords were spelled correctly representing the high orthotactic probability condition $(M=0.65, S D=0.13)$ than the low orthotactic probability condition $(M=0.50, S D=0.12)$. The main effect for phonotactic probability and the interaction between phonotactic and orthotactic probabilities were not significant. On the recognition task, there were no significant main effects or interactions (all $p s>.05$ ).

\section{Initial MGR acquisition abilities based on written word recognition skills}

Similar to other investigators of children's initial MGR learning (e.g., Ehri \& Saltmarsh, 1995; Ehri \& Wilce, 1985; Wright \& Ehri, 2007), we examined the influence of written word recognition on initial MGR acquisition by forming two subgroups of readers (i.e., less advanced and more advanced beginning readers; $N \mathrm{~s}=25$ and 21 , respectively), based on a median split of the scores on the WRMT-R Word Identification task, a measure of real word reading. We chose to develop subgroups based on the Word Identification task because, as a measure of an individual's stored MGRs, it seemed closest to the focus of the study: the development of initial MGRs. The mean standard score for the less advanced beginning readers was $91.40(S D=5.31)$; the mean standard score for the more advanced beginning readers was $110.67(S D=11.19)$. Independent sample $t$ tests revealed that the two subgroups did not differ by age, receptive vocabulary, letter identification, nonsense word reading (WRMT-R word attack), and nonverbal cognition (all $p \mathrm{~s}>.05$ ). As anticipated, the more advanced beginning readers performed significantly higher on the WRMT-R word identification, $t(44)=$ $-7.66, p<.001, d=2.2$. They also achieved significantly higher scores on the phonemic awareness composite, $t(44)=-2.72, p=.009, d=0.79$, and spelling measure, $t$ (44) $=-3.18, p=.003, d=0.94$. The differences in phonemic awareness seemed to be the result of significantly higher scores on the segmenting subtest, $t(44)=-4.03, p>.001, d=1.17$, and the blending subtest, $t(44)=$ $-2.98, p=.005, d=0.88$. No differences were found for the RAAT $(p>$ .05 ; see Table 2 for subgroups' means and standard deviations on nonverbal 
cognition, vocabulary, spelling, and letter identification measures and the reading and phonemic awareness composite scores).

A $2 \times 2 \times 2$ repeated measures ANOVA was conducted with the between-group factor of subgroup, again using a Bonferroni correction $(p=.025)$. On the production task (partial scoring), the advanced beginning readers spelled significantly more words $(M=3.62, S D=4.14)$ than the less advanced beginning readers $(M=$ $\left.1.2, S D=2.0, F=6.7, p=.013, \eta^{2}=0.13\right)$. There also was a significant main effect for orthotactic probability (more high orthotactic probability words spelled correctly; $F=5.78, \mathrm{p}=.021, \eta^{2}=0.12$ ). No other comparisons were significant. A similar ANOVA was conducted for the recognition task. The more advanced beginning readers identified more words $(M=7.29, S D=3.54)$ than the less advanced beginning readers $\left(M=5.04, S D=3.03, F=5.37, p=.025, \eta^{2}=0.11\right)$. There were no other significant main effects or interactions. Thus, although the more advanced beginning readers demonstrated greater initial MGR acquisition in general (in both production and recognition tasks), the impact of the words' statistical regularities was not different for the two groups.

\section{Predicting reading and spelling performance}

The final regression analyses sought to determine whether the children's initial MGR learning abilities explained unique variance on their performance on the reading and spelling measures beyond that explained by other known contributors to literacy: receptive vocabulary, phonemic awareness, letter identification, and nonverbal cognition. Before conducting the regressions, a composite MGR learning score was calculated by summing the children's performance on the production (using the partial scoring) and recognition tasks, which were significantly related $(r=.76, p<.001)$. The reliability coefficient for the experimental procedure using the composite score was acceptable $(\alpha=0.86)$. Regression analyses were conducted using the entire group of children.

The results of a Pearson product moment correlational analysis revealed moderate to strong significant correlations between the composite reading score and the MGR learning composite, letter identification, receptive vocabulary, nonverbal cognition, and phonemic awareness composite scores (see Table 3). Similarly, there were moderate to strong and significant associations between the spelling score and the MGR learning composite, letter identification, receptive vocabulary, and phonemic awareness composite scores. The significantly correlated variables were entered into two hierarchical linear regression analyses to assess whether the MGR learning composite score accounted for significant variance on the measures of reading and spelling above other known, associated predictor variables.

For the first regression, phonemic awareness, receptive vocabulary, letter identification, and nonverbal cognition were entered into the first step. Combined, the four measures accounted for $56 \%$ of the variance on the reading composite score (adjusted $\left.r^{2}=.52, p<.001\right)$. When entered into the second step, MGR learning accounted for an additional $18 \%$ of the variance on reading (adjusted $r^{2}=.71, p<$ .001 ; see Table 4). For the second regression, the same predictor variables, except for nonverbal cognition, were entered into the first step, which accounted for $46 \%$ 
Apel et al.: Acquisition of initial MGRs

Table 3. Relations among MGR acquisition and literacy

\begin{tabular}{lccccccc}
\hline \hline \multicolumn{1}{c}{ Task } & 1 & 2 & 3 & 4 & 5 & 6 & 7 \\
\hline 1. Spelling & - & $.63^{* * *}$ & $.40^{* * *}$ & $.47^{* * *}$ & .23 & $.61^{* * * *}$ & $.67^{* * * *}$ \\
2. Reading composite & - & - & $.37^{* *}$ & $.41^{* * *}$ & $.49^{* * *}$ & $.66^{* * *}$ & $.73^{* * * *}$ \\
3. Receptive vocabulary & - & - & - & $.52^{* * *}$ & .24 & $.62^{* * *}$ & $.43^{* * *}$ \\
4. Letter identification & - & - & - & - & $.47^{* * *}$ & $.37^{* *}$ & $.51^{* * *}$ \\
5. Nonverbal cognitive & - & - & - & - & - & .26 & .21 \\
6. Phonemic awareness & & & & & & & $.55^{* * *}$ \\
$\quad$ composite & - & - & - & - & - & - & - \\
\hline \hline
\end{tabular}

Note: MGR, mental graphemic representations; Reading composite, work attack and word identification subtests of Woodcock Reading Mastery Test; Receptive vocabulary, standard score from Peabody Picture Vocabulary Test, 3rd or 4th edition; Letter identification, raw score, letter identification subtest of Woodcock Reading Mastery Test; Nonverbal cognitive, standard score from nonverbal subtest of the Kaufman Brief Intelligence Test, 2nd Edition; MGR acquisition, total production and recognition using the partial scoring system.

$* * p<.01 . * * * p=.001$.

Table 4. Summary of regression analysis for factors affecting reading composite $(N=46)$

\begin{tabular}{lcccccc}
\hline \hline \multicolumn{1}{c}{ Variables } & $R^{2}$ & $\Delta R^{2}$ & Adj. $R^{2}$ & $F$ & $p$ & $d f$ \\
\hline Literacy tasks & .56 & .56 & .52 & 13.13 & $<.001^{*}$ & 1,41 \\
Total MGR acquisition & .74 & .18 & .71 & 27.32 & $<.001^{*}$ & 1,40 \\
\hline \hline
\end{tabular}

Note: Literacy tasks included Kaufman Brief Intelligence Test, 2nd Edition, Peabody Picture Vocabulary Test, letter identification, and phonological composite. Total MGR acquisition, total mental graphemic representations production and recognition using the partial scoring system.

$* p<.05$.

of the variance on spelling (adjusted $r^{2}=.42, p<.001$ ). MGR learning explained an additional $10 \%$ of the variance on spelling when entered into the second step (adjusted $r^{2}=.51, p=.005$; see Table 5).

\section{DISCUSSION}

In this investigation, we sought to determine the extent to which kindergarten children at risk for literacy development acquired initial MGRs, whether the linguistic regularities of target nonwords influenced their ability to acquire initial MGRs, whether subgroups of these children who varied in word recognition skills differed in their initial MGR learning abilities, and whether initial MGR acquisition ability uniquely predicted performance on measures of reading and 
Apel et al.: Acquisition of initial MGRs

Table 5. Summary of regression analysis for factors affecting spelling $(N=46)$

\begin{tabular}{lcccccc}
\hline \hline \multicolumn{1}{c}{ Variables } & $R^{2}$ & $\Delta R^{2}$ & Adj. $R^{2}$ & \multicolumn{1}{c}{$F$} & $p$ & $d f$ \\
\hline Literacy tasks & .46 & .46 & .42 & 11.77 & $<.001^{*}$ & 1,42 \\
Total MGR acquisition & .55 & .10 & .51 & 8.89 & $.005^{*}$ & 1,41 \\
\hline \hline
\end{tabular}

Note: Literacy tasks include Peabody Picture Vocabulary Test, letter identification, and phonological composite. Total MGR acquisition, total mental graphemic representations production and recognition using the partial scoring system.

$* p<.05$.

spelling ability above that explained by known predictors. Previous studies of initial MGR acquisition revealed that preschool and kindergarten children from middle SES backgrounds quickly acquire initial MGR information after minimal exposure to new, written nonwords. We hypothesized that the at-risk children would acquire less initial MGR information than their non-at-risk peers and that the two subgroups of these children would differ from each other in their MGR learning skills. These predictions were based on past reports of the poorer literacy abilities of children from low SES backgrounds, compared to children from middle SES backgrounds and the notion that larger vocabularies, or in our case the MGR lexicons, aid word learning (e.g., Duncan \& Seymour, 2000; Gershkoff-Stowe \& Hahn, 2007; Thomas-Tate et al., 2006). We further predicted that the nonwords' linguistic properties would affect the children's initial MGR acquisition ability and that the children's ability to quickly acquire initial MGR information would contribute uniquely to their performance on reading and spelling measures. The results of the study confirmed these four hypotheses.

\section{Initial MGR learning ability}

Our participants appeared to acquire some initial MGR information, particularly as demonstrated on the recognition task, although considerably less than past reports of initial MGR acquisition (Apel, 2010; Apel et al., 2006; Evans et al., 2008; Wolter $\&$ Apel, 2010). On the production task using the complete scoring procedure, $24 \%$ of our participants spelled at least one novel word correctly; $46 \%$ were credited with spelling at least one word correctly using the partial scoring procedure. In addition, approximately two-thirds (63\%) of our participants identified more than four target nonwords (i.e., above chance level) on the recognition task. Although our findings indicate that some initial MGR information was acquired, the percentage of correct responses on both tasks was notably lower than past reports of kindergarten children from middle SES backgrounds. For example, $78 \%$ to $90 \%$ of the kindergarten, middle SES children in two previous studies spelled at least one word correctly (using full scoring); $95 \%$ to $100 \%$ of these same children identified more target words correctly above the level of chance (i.e., Apel, 2010; Wolter \& Apel, 2010). A higher percentage of preschool children (29\%) and kindergarten children with language impairment $(36 \%)$ spelled at least one word correctly than did our participants (Apel et al., 2006; Wolter \& Apel, 2010). Similarly, 
the preschool children and kindergarten children with language impairment in previous studies identified more target words above chance level (i.e., $75 \%$ and $68 \%$, respectively) than did our participants.

There are several potential sources for the less robust initial MGR learning demonstrated by the children in our study. For example, age might play a role in initial MGR learning. Our kindergarten participants were younger $(5 ; 9)$ than the children in Apel (2010) and Wolter and Apel (2010), whose mean age was 6;2. Although our participants were 3 months younger, testing took place at approximately the same time of the kindergarten academic year across the three studies, suggesting the children had roughly equivalent amounts of exposure to schoolbased activities that potentially promote active MGR learning (e.g., storybook reading; Justice, 2002; Justice et al., 2009). In addition, the preschool children in Apel et al. (2006), who were younger than our participants and likely had less formal academic experience, performed better on the production and recognition tasks than our participants. Thus, age differences across studies do not seem to explain performance differences well.

Unlike the children in the previous studies (Apel, 2010; Apel et al., 2006; Wolter \& Apel, 2010), our participants were from low SES backgrounds. Past reports (e.g., Hart \& Risley, 1995; Washington, 2001) suggest that children from low SES backgrounds have less exposure to storybook reading activities. Thus, a second explanation for differences between our findings and those of past investigations may be that the experimental MGR learning procedure, which required children to respond to specific questions about a story read, represented an unfamiliar task to the children; that is, their lack of experience with the task, a shared storybook experience, may have interfered with their performance. Again, one caveat to this possible cause is that our participants had been enrolled in kindergarten for at least 5 months. Presumably, classroom experiences included activities similar to the experimental MGR learning procedure (i.e., storybook reading followed by questions) so that the experimental MGR learning procedure was not entirely novel.

A third explanation for the differences may be tied to the spoken vocabulary knowledge of the children. Although the mean vocabulary standard score for the total group of participants $(M=97)$ as well as the mean scores for the two subgroups (i.e., less advanced beginning readers, $M=96$; more advanced beginning readers, $M=98$ ) was slightly below average, they were close to the standardized mean score. However, our participants' mean score was notably lower than those reported in previous investigations of preschool and kindergarten children from middle SES backgrounds (i.e., standard scores of 107 in Apel et al., 2006; and 113 in Apel, 2010). The difference in mean vocabulary scores between children from low and middle SES backgrounds was somewhat expected. Previous research has shown that children from low SES backgrounds have less exposure to a broad vocabulary base and lower receptive vocabulary scores on norm-referenced measures (Brooks-Gunn, Klebanov, \& Duncan, 1996; Campbell, Bell, \& Keith, 2001; Hart \& Risley, 1995). In addition, previous studies have consistently found that African American students from low-SES backgrounds perform about 10 points below the mean on the Peabody Picture Vocabulary Test and other standardized vocabulary measures (Restrepo et al., 2006; Thomas-Tate 
et al., 2006; Washington \& Craig, 1999). Some researchers have suggested that children with smaller vocabularies learn less information initially about new words than children with larger vocabularies (e.g., Gershkoff-Stowe \& Hahn, 2007); this claim, however, was made for spoken word learning. Regardless, a negative impact of reduced vocabulary on MGR learning does not fit the findings from our two subgroups of participants. The vocabulary skills of the two subgroups were highly similar yet the less advanced group performed significantly poorer that the more advanced group on the MGR learning tasks. Further, the kindergarten children with language impairment in Wolter and Apel (2010) demonstrated vocabulary skills 1 or more standard deviations below the standardized mean yet these children scored higher on the MGR learning tasks than our participants. Thus, spoken vocabulary size does not appear to help explain differences in MGR learning ability.

Our participants' letter knowledge skills were within typical limits. In addition, the two subgroups did not differ in their letter knowledge skills even though they differed in their initial MGR acquisition skills. Thus, letter knowledge likely did not play a role in the children's performance on the experimental MGR learning procedure. As a group, our participants responded correctly to $40 \%$ of the items on the phonemic awareness tasks, which was less than reported responses for kindergarten from middle SES backgrounds (e.g., 65\% in Apel, 2010). Our less advanced beginning readers also demonstrated significantly lower phonemic awareness skills than the more advanced beginning readers on two of the three phonemic awareness tasks. At first, these differences in phonemic awareness might suggest phonological skills impacted MGR learning. However, given that the whole group as well as the individual subgroups achieved mean standard scores within typical limits on a norm-referenced measure of nonsense word reading (WRMT-R word attack subtest), which taps into phonemic awareness as well as letter knowledge, this explanation for differences in initial MGR learning based on phonemic awareness abilities seems unlikely. Further, the two subgroups did not differ significantly in their decoding skills yet they demonstrated significant differences in MGR learning. As suggested by others (e.g., Rosenthal \& Ehri, 2008), the task itself likely did not require the children to apply phonological skills, such as phonological recoding, because the words were read to the children. Differences in phonemic awareness or phonological decoding abilities, then, do not appear to be a viable explanation for differences in MGR learning.

The most likely explanation for differences in initial MGR learning is the size of the children's MGR lexicon, the orthographic or written language equivalent to spoken vocabulary. Size of the MGR lexicon was determined by the children's performance on the WRMT-R word identification subtest, a measure of realword reading. First, although as a whole group, the children performed within typical limits $(M=100, S D=12.83)$, their scores were notably different than past reports of similar-age kindergarten children with middle SES backgrounds (e.g., $M=114, S D=13.01$; Apel, 2010). In addition, inspection of the mean scores for our two subgroups lends support to the supposition that the size of the MGR lexicon impacts initial MGR learning (cf. Gershkoff-Stowe \& Hahn, 2007). Children in the more advanced beginning reading group, who appeared to have significantly larger MGR lexicons than the less advanced beginning readers as 
demonstrated by their scores on the WRMT-R word identification subtest (i.e., mean standard score of $110 \mathrm{vs.} 91$ for the less advanced beginning reading group), also provided more correct responses on the production and recognition tasks. Thus, similar to previous findings of the initial spoken word learning skills of children from middle SES backgrounds (Gershkoff-Stowe \& Hahn, 2007), the breadth of previously stored written word representations appears to affect the amount of initial information learned about new written words.

Although the supposition that larger MGR lexicons lead to more initial word information gleaned during first word exposures aligns with suggestions from spoken word learning studies (Gershkoff-Stowe \& Hahn, 2007) and is supported by the subgroup differences in initial written-word learning in our study, an explanation for the entire groups' lower performance, compared to past reports, is needed. Investigators have documented that children from low SES backgrounds and African American children do not typically have the same amount and/or type of exposure to print and reading experiences as their middle SES counterparts. As suggested by Gershkoff-Stowe and Hahn (2007), one aspect to larger vocabularies is an automaticity in word learning; with consistent and frequent practice, the process becomes more and more automated. Thus, it may be that our participants, although demonstrating adequate MGR lexicons, came to the task of learning our nonwords with less experience and/or practice with the written wordlearning process. When adults engage children in text-related print activities, such as storybook reading, there is some degree of attention given to word forms (e.g., "Look, this word says Spot!"). These attention-drawing strategies likely provide children with a better appreciation for and indication of the need to develop MGRs (e.g., Justice et al., 2009). Because young children in at-risk groups may not have the same frequency or quality of print interactions as children from nonat-risk groups (e.g., Roberts et al., 2005; Vernon-Feagans et al., 2001), they may have less proficient and automatic MGR-learning skills. Future MGR-learning studies that record the initial MGR acquisition skills of children from at-risk groups while also documenting the frequency and quality of their print-related and reading experiences will add needed insight into the differences in initial MGR acquisition.

\section{Influences of linguistic statistical regularities on initial MGR learning}

The orthographic properties of words affected our participants' initial MGR acquisition. Like previous reports of preschool and kindergarten children from middle SES backgrounds (e.g., Apel, 2010; Apel et al., 2006; Wolter \& Apel, 2010), our at-risk participants spelled more nonwords in the high orthotactic probability condition than the low orthotactic probability condition. It is important to note that, given that probability and neighborhood density were not systematically varied, it may be that the obtained effects were due to word densities rather than probabilities. Nevertheless, the results provide evidence for the effect of linguistic statistical regularities on initial MGR learning in children from at-risk groups.

The influence of statistical regularities on initial MGR acquisition is highly notable for several reasons. First, the orthotactic probability effect may have occurred 
because the children more efficiently stored new MGR information for words that were similar in their probabilities to those contained in their MGR lexicons. This hypothesis aligns with Storkel's (2009) word-learning theory. Storkel suggests that children more efficiently learn words when those words' lexical probabilities match those of previously stored representations. It may be that our findings, and those of previous investigations (e.g., Apel, 2010; Apel et al., 2006; Wolter \& Apel, 2010), suggest that it is not the size of the mental lexicon that influences word learning but rather the number of representations within that lexicon that contain similar lexical or sublexical characteristics to the novel words being learned.

A second implication of the effect of orthotactic probability on our participants' initial MGR learning is that the influence was evident in both more advanced and less advanced beginning readers. Thus, even with beginning readers who may not have reached a level of word-learning proficiency as their more advanced counterparts, they still utilize the statistical probabilities of orthography as a bootstrap in that word-learning process. The finding suggests the powerful role orthographic knowledge, albeit implicit, plays in early MGR-learning development.

The finding that orthotactic probability influenced our at-risk participants' initial MGR development provides evidence that they were implicitly sensitive to orthographic regularities. This finding is remarkable given a rather robust literature that demonstrates the different type of exposure to print that children from at-risk populations receive compared to their middle SES peers (e.g., Levy et al., 2006; Stephenson, Parilla, Georgiou, \& Kirby, 2008). Typically, these differences in print and reading experiences are viewed as negative or less than optimal. It is possible that less exposures to active engagement with print (e.g., informal writing activities, adult-led storybook reading) lead to the less than expected level of overall initial MGR learning found in our study. Developing a specific MGR requires multiple exposures to a specific word form. With fewer exposures to specific words, a large MGR lexicon cannot be formed, reducing the positive influence a broad MGR lexicon has on further MGR learning. However, it is important to note that the experiences with print that the children received appeared to provide enough exposures for them to develop broad sensitivities to the orthographic regularities of written words. This latter point speaks to the different learning requirements for developing knowledge of orthotactic probabilities versus specific MGRs. It appears, similar to reports of phonotactic probability learning in infants and young children (e.g., Jusczyk et al., 1994; Mattys \& Lusczyk, 2001), that orthotactic probabilities are learned early with relatively minimal exposure and no explicit adult-led attention. Thus, it seems less exposure to print does not impact children's ability to develop sensitivities to words' statistical properties; it does, however, affect their ability to learn specific MGRs, possibly because of a reduced overall MGR lexicon that is less facilitative of further MGR learning.

Similar to the findings of Apel (2010) for kindergarten children from middle SES backgrounds, our participants' initial MGR learning abilities were not affected by the phonotactic probabilities of the target nonwords. These results suggest that the children utilized their existing orthographic knowledge (i.e., implicit knowledge 
of orthographic regularities) to guide learning, rather than their knowledge of the phonological system. The lack of a phonotactic probability effect suggests that limited phonological recoding occurred because low phonotactic probability likely would increase the cognitive demands to blend sounds once they had been recoded from letters. Our findings do not diminish the well-documented importance of phonological knowledge to early reading and spelling (e.g., Bird, Bishop, \& Freeman, 1995; Ehri, Nunes, Willows, Schuster, Yaghoub-Zadeh, \& Shanahan, 2001; Torgeson, Wagner, \& Rashotte, 1994); however, our findings, coupled with those of past investigations (e.g., Apel, 2010; Apel et al., 2006; Wolter \& Apel, 2010), suggest that orthographic knowledge plays an equally important and valuable role early in development.

The participants' performance on the recognition task was unaffected by words' linguistic probabilities. The children also obtained higher scores on the recognition task than the production task. The production task required a child to recall specific MGR information; the recognition task required the child to match a visible stimulus to a newly stored initial MGR. As such, performance on the production task, certainly the more stringent measure of the initial MGR instantiated, was facilitated by the common orthotactic patterns in some of the nonwords, suggesting that the employment of implicit knowledge of the linguistic regularities of words may aid the depth of initial learning and subsequent retrieval of that information.

\section{Predicting reading and spelling performance}

Our participants' performance on the written word-learning procedure was strongly associated with reading and spelling ability and uniquely predicted $18 \%$ and $10 \%$ unique variance on the reading and spelling measures, respectively, above other known foundational skills. These findings are similar to those reported in past investigations of initial MGR acquisition in preschool and kindergarten children from middle SES backgrounds (Apel, 2010; Apel et al., 2006). Our results suggest that the ability to acquire initial MGRs, as measured in an experimental MGR learning procedure, represents a separate and important contributing factor to early literacy development.

The significant contributions of initial MGR learning ability to reading and spelling, coupled with the children's apparent sensitivity to the orthographic regularities in written language, contrasts with traditional stage theories of literacy development (e.g., Ehri, 1992; Share, 1995). Such stage theories place the role of phonological knowledge early in development and suggest that children, through self-teaching, develop initial MGRs by phonologically recoding written words, bonding the words' pronunciations to their orthographic representations. This did not appear to be the case in our study. Given our participants' beginning level of phonological recoding skills and the minimal need to recode the words because the adult read the words aloud (e.g., Rosenthal \& Ehri, 2008), it appears that selfteaching, at least in the traditional sense of overtly sounding out words, did not play a large role in establishing initial MGRs. Instead, the children used their implicit orthographic knowledge to bootstrap learning of the initial representations. This influence of orthography early in development is contrary to most accounts of 
stage theories. However, it aligns with other theories that suggest multiple sources of linguistic knowledge are employed early in development of reading and spelling (e.g., Apel, Masterson, \& Hart, 2004; Siegler, 1996).

It is important that, although the ability to develop some initial MGR information was highly related to reading and spelling in our at-risk participants, their overall MGR development skills were notably different than those of their middle SES counterparts previously reported. In addition, it should be noted that the composite scores used to examine the variance explained by performance on the written word learning procedure included production task scores obtained using the partial scoring system, a procedure that credited correct spelling for both correct and approximate word spellings. It may be that, had we used the original scoring system, the lack of variability in scores would have prevented any meaningful outcomes to be obtained.

There are several limitations of this study, some of which have been discussed in previous investigations (e.g., Apel, 2010) and each of which can be addressed in future investigations. For example, the children in this study, contrary to some previously published reports of at-risk groups, presented with average reading and vocabulary abilities. It may be that other studies that include children with a broader range of language and reading abilities will result in some different outcomes. In addition, the nonwords represented unfamiliar vocabulary, all of which were nouns. Although older, more mature readers do not seem to differ in their initial acquisition of MGRs based on familiarity with a word (Share, 2004), it is important to document whether this is true for younger, beginning readers. In addition, other word types may pose additional challenges, based on studies of spoken word acquisition (e.g., Rice \& Woodsmall, 1988). Third, the study was designed to assess initial MGR acquisition with a specific focus on the orthographic form of the new nonwords. It remains to be determined how children at risk for literacy development quickly acquire the semantic information for novel words and the retention of word information (i.e., orthographic and semantic) across time.

Many of our participants were African American and were judged to use some form of AAE dialect, although no formal measure of AAE use was obtained. The stories in the MGR learning procedure were read using Standard American English dialect. Although future investigations are encouraged to obtain specific measures of AAE use, differences in dialects between the procedure and the participants should not affect MGR learning given that English orthography is written in a unitary standard manner. Certainly, the finding that the statistical regularities of our nonwords affected our participants' initial MGR learning suggest that dialectal differences did not impede the facilitative effects of words' statistical properties on initial MGR learning.

One final limitation, which leads to rather interesting future investigations, relates to the stimuli used for the experimental MGR learning procedure. As noted earlier, statistical probability and neighborhood density were not systematically varied; thus, it is not possible to determine whether the obtained effects were due to word densities or probabilities. As postulated earlier, it may be that reduced amounts of experiences with literacy activities lead to reduced MGR lexicons, which in turn led to poor MGR learning in our investigation. In this case, the 
facilitative effects of words statistical properties were likely due to orthotactic probabilities (i.e., high orthotactic probability words triggered the children to start the learning process) rather than to neighborhood density (i.e., there would be less stored mental representations that share orthographic-lexical characteristics with the new words; cf. Storkel, 2009). The exact nature of the effects of words statistical regularities on initial MGR learning, and the implications for literacy development, should be explored in the future.

\section{CONCLUSION}

Our findings suggest that kindergarten children from at-risk populations acquire some initial MGR information quickly, subgroups of these children with varying levels of word recognition skills differ in their initial MGR acquisition abilities, and that these children's MGR learning is affected by the orthographic regularities of written language. In addition, their ability to acquire initial MGRs explains their performance on measures of reading and spelling above that predicted by other known foundational skills. Although this pattern of performance is similar to past reports of kindergarten children from middle SES backgrounds who were primarily Caucasian, it is important to note that the amount of information learned, as measured on the MGR-learning procedures, was not at the expected level based on these past reports. Thus, the data speak to the importance of increasing the print and reading experiences of children from at-risk groups to improve their literacy skills. Investigators have provided several models for intervention that would likely increase these children's experiences and exposure to print (e.g., Aram \& Biron, 2004; Justice et al., 2009).

The ability to quickly develop some initial MGR information, as evidenced in the MGR-learning procedure, contributes to early reading and spelling development. Our findings support previous suggestions (e.g., Nation, Angell, \& Castles, 2007; Share, 1995) that young children, before they typically develop more mature phonological recoding abilities, demonstrate a level of awareness for, and inclination to learn, the written form of words. Although more advanced readers also may use other means to acquire initial MGRs (e.g., phonological recoding; Ehri, 1992; Share, 1995), this investigation, along with several previous studies (Apel, 2010; Apel et al., 2006; Evans et al., 2008; Wolter \& Apel, 2010), suggests that young children swiftly develop some initial MGR information, incidentally extracting that information and quickly storing it for later use. With additional studies that examine MGR acquisition longitudinally, a better picture of how children acquire these important mental representations will emerge. 


\section{APPENDIX A: SAMPLE EXPERIMENTAL TASK POWERPOINT} SLIDE PRESENTATION

\section{Story Presentation Slide 1}

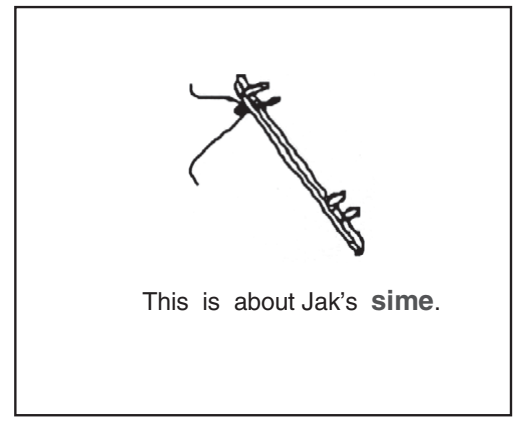

Story Presentation Slide 3

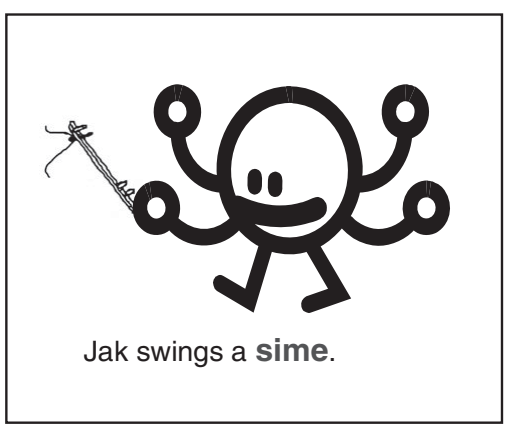

Spelling Production Slide 4 Examiner: "Write what this thing is called."

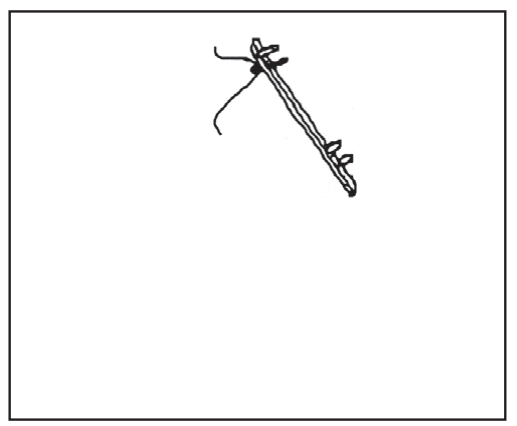

Story Presentation Slide 2

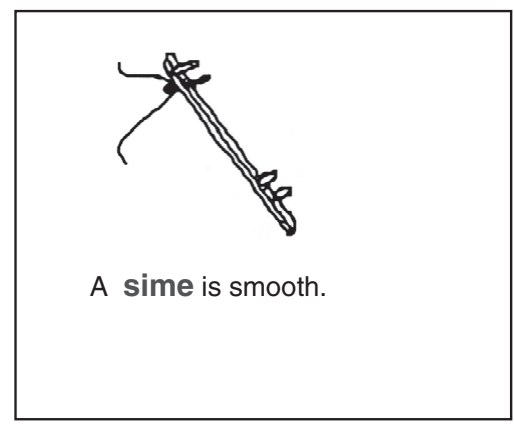

Story Presentation Slide 4

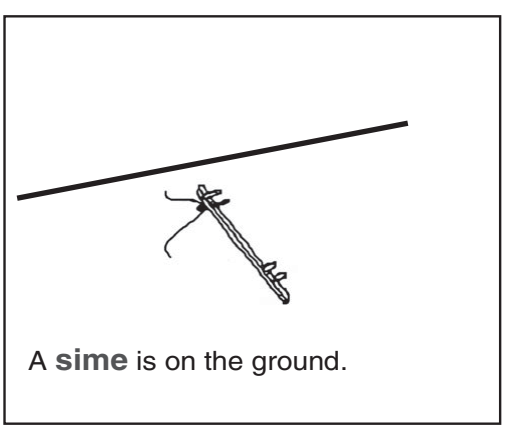

Spelling Identification Slide 5

Examiner: "Which one of these is what this thing is called?"

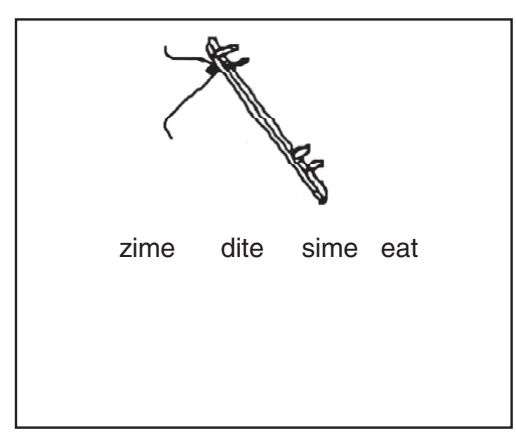


Apel et al.: Acquisition of initial MGRs

\section{NOTE}

1. Various terms have been used to label word-specific representations of written words in memory, including word spellings (e.g., Rosenthal \& Ehri, 2008), sight word or visual spellings (e.g., Ehri \& Rosenthal, 2007), and orthographic images (e.g., Cunningham, 2006), to name a few. In this paper, the term MGR is used to represent the stored, mental image of a specific word.

\section{REFERENCES}

Adams, M. (1990). Beginning to read: Thinking and learning about print. Cambridge, MA: MIT Press. Anderson-Yockel, J., \& Haynes, W. O. (1994). Joint book-reading strategies in working-class African American and White mother-toddler dyads. Journal of Speech and Hearing Research, 37, 583-593.

Apel, K. (2010). Kindergarten children's initial spoken and written word learning in a storybook context. Scientific Studies of Reading, 14, 440-463.

Apel, K., \& Masterson, J. J. (2001). Theory-guided spelling assessment and intervention: A case study. Language, Speech, and Hearing Services in the Schools, 32, 182-195.

Apel, K., Masterson, J. J., \& Hart, P. (2004). Integration of language components in spelling: Instruction that maximizes students' learning. In E. R. Silliman \& L. C. Wilkinson (Eds.), Language and literacy learning in schools (pp. 292-315). New York: Guilford Press.

Apel, K., Wolter, J. A., \& Masterson, J. J. (2006). Effects of phonotactic and orthotactic probabilities during fast-mapping on five year-olds' learning to spell. Developmental Neuropsychology, 29, $21-42$.

Aram, D., \& Biron, S. (2004). Joint storybook reading and joint writing interventions among low SES preschoolers: Differential contribution to early literacy. Early Childhood Research Quarterly, $19,588-610$.

Bird, J., Bishop, D. V. M., \& Freeman, N. H. (1995). Phonological awareness and literacy development in children with expressive phonological impairments. Journal of Speech and Hearing Research, 38, 446-462.

Brooks-Gunn, J., Klebanov, P. K., \& Duncan, G. J. (1996). Ethnic differences in children's intelligence test scores: Role of economic deprivation, home environment, and maternal characteristics. Child Development, 67, 396-408.

Bus, A. G., van IJzendoorn, M. H., \& Pelligrini, A. D. (1995). Joint book reading makes for success in learning to read: A meta-analysis on intergenerational transmission of literacy. Review of Educational Research, 65, 1-21.

Campbell, J. M., Bell, S. K., \& Keith, L. K. (2001). Concurrent validity of the Peabody Picture Vocabulary Test-Third Edition as an intelligence and achievement screener for low SES African American children. Assessment, 8, 85-94.

Cleary, A. M., Morris, A. L., \& Langley, M. M. (2007). Recognition memory for novel stimuli: The structural regularity hypothesis. Journal of Experimental Psychology: Learning, Memory, and Cognition, 33, 379-393.

Craig, H. K., Connor, C. M., \& Washington, J. A. (2003). Early positive predictors of later reading comprehension for African American students: A preliminary investigation. Language, Speech, and Hearing Services in Schools, 34, 31-43.

Craig, H. K., \& Washington, J. A. (2004). Grade related changes in the production of African American English. Journal of Speech, Language, and Hearing Research, 47, 450-463.

Cunningham, A. E. (2006). Accounting for children's orthographic learning while reading text: Do children self-teach? Journal of Experimental Child Psychology, 95, 56-77.

Duncan, L. G., \& Seymour, P. H. K. (2000). Socioeconomic differences in foundation-level literacy. British Journal of Psychology, 91, 145-166.

Dunn, L. M., \& Dunn, L. M. (1997). Peabody Picture Vocabulary Test (3rd ed.). Circle Pines, MN: American Guidance Service.

Dunn, L.M., \& Dunn, L.M. (2007). Peabody Picture Vocabulary Test (4th ed.). Circle Pines, MN: American Guidance Service. 
Apel et al.: Acquisition of initial MGRs

Ehri, L. C. (1992). Reconceptualizing the development of sight word reading and its relationship to recoding. In P. Gough, L. C. Ehri, \& R. Treiman (Eds.), Reading acquisition (pp. 107-143). Hillsdale, NJ: Erlbaum.

Ehri, L. C., Nunes, S. R., Willows, D. M., Schuster, B. V., Yaghoub-Zadeh, Z., \& Shanahan, T. (2001). Phonemic awareness instruction helps children learn to read: Evidence from the National Reading Panel's meta-analysis. Reading Research Quarterly, 36, 250-287.

Ehri, L. C., \& Rosenthal, J. (2007). Spellings of words: A neglected facilitator of vocabulary learning. Journal of Literacy Research, 39, 389-409.

Ehri, L. C., \& Saltmarsh, J. (1995). Beginning readers outperform older disabled readers in learning to read words by sight. Reading and Writing, 7, 295-326.

Ehri, L. C., \& Wilce, L. S. (1985). Movement into reading: Is the first stage of printed word learning visual or phonetic? Reading Research Quarterly, 20, 163-179.

Ehri, L. C., \& Wilce, L. S. (1987a). Does learning to spell help beginners learn to read words? Reading Research Quarterly, 22, 47-65.

Ehri, L. C., \& Wilce, L. S. (1987b). Cipher versus cue reading: An experiment in decoding acquisition. Journal of Educational Psychology, 79, 3-13.

Evans, M. A., Williamson, K., \& Pursoo, T. (2008). Preschoolers' attention to print during shared book reading. Scientific Studies of Reading, 12, 106-129.

Gershkoff-Stowe, L., \& Hahn, E. R. (2007). Fast mapping skills in the developing lexicon. Journal of Speech, Language, and Hearing Research, 50, 682-696.

Gray, S. (2005). Word learning by preschoolers with specific language impairment: Effect of phonological or semantic cues. Journal of Speech, Language, and Hearing Research, 48, 14521467.

Gray, S. (2006). The relationship between phonological memory, receptive vocabulary, and fast mapping in young children with specific language impairment. Journal of Speech, Language, and Hearing Research. 49, 955-969.

Hart, B., \& Risley, T. (1995). Meaningful differences in the everyday experiences of young children. Baltimore, MD: Paul H. Brookes.

Heath, S. B. (1983). Ways with words: Language, life, and work in communities and classrooms. New York: Cambridge University Press.

Hoff, E. (2003). The specificity of environmental influence: Socioeconomic status affects early vocabulary development via maternal speech. Child Development, 74, 1368-1378.

Horton-Ikard, R., \& Weismer, S. E. (2007). A preliminary examination of vocabulary and word learning in African American toddlers from middle and low socioeconomic status homes. American Journal of Speech-Language Pathology, 16, 381-392.

Johnson, V. (2001). Fast mapping verb meaning from argument structure. Unpublished doctoral dissertation. University of Massachusetts, Amherst.

Jusczyk, P. W., Luce, P. A., \& Charles-Luce, J. (1994). Infants' sensitivity to phonotactic patterns in the native language. Journal of Memory and Language, 33, 630-645.

Justice, L. M. (2002). Word exposure conditions and preschoolers' novel word learning through reading. Reading Psychology, 23, 87-106.

Justice, L. M., Kaderavek, J. N., Fan, X., Sofka, A., \& Hunt, A. (2009). Accelerating preschoolers' early literacy development through classroom-based teacher-child storybook reading and explicit print referencing. Language, Speech, and Hearing Services in Schools, 40, 67-85.

Justice, L. M., Pullen, P. C., \& Pence, K. (2008). Influence of verbal and nonverbal references to print on preschoolers' visual attention to print during storybook reading. Developmental Psychology, $44,855-866$.

Kaufman, A. S., \& Kaufman, A. L. (2004). Kaufman Brief Intelligence Test. Circle Pines, MN: American Guidance Service.

Kessler, B., \& Treiman, R. (2001). Relationships between sounds and letters in English monosyllables. Journal of Memory and Language, 44, 592-617.

Klauda, S. L., \& Guthrie, J. T. (2008). Relationships of three components of reading fluency to reading comprehension. Journal of Educational Psychology, 100, 310-321.

Levy, B. A., Gong, Z., Hessels, S., Evans, M. A., \& Jared, D. (2006). Understanding print: Early reading development and the contributions to home literacy experiences. Journal of Experimental Child Psychology, 95, 63-93. 
Apel et al.: Acquisition of initial MGRs

Lonigan, C. J., Burgess, S. R., \& Anthony, J. L. (2000). Development of emergent literacy and early reading skills in preschool children: Evidence from a latent variable longitudinal study. Developmental Psychology, 36, 596-613.

Marchman, V. A., \& Fernald, A. (2008). Speed of word recognition and vocabulary in infancy predict cognitive and language outcomes in later childhood. Developmental Science, 11, F9F16.

McCardle, P., Scarborough, H. S., \& Catts, H. W. (2001). Predicting, explaining, and preventing children's reading difficulties. Learning Disabilities Research and Practice, 16, 230-239.

Mattys, S., \& Lusczyk, P. W. (2001). Phonotactic cues for segmentation of fluent speech by infants. Cognition, 78, 91-121.

Molfese, V. J., Modglin, A. A., Beswick, J. L., Neamon, J. D., Berg, S. A., Berg, C. J., et al. (2006). Letter knowledge, phonological processing, and print knowledge: Skill development in nonreading preschool children. Journal of Learning Disabilities, 39, 296-305.

Munson, B., Kurtz, B. A., \& Windsor, J. (2005). The influence of vocabulary size, phonotactic probability, and wordlikeness on nonword repetitions of children with and without specific language impairment. Journal of Speech, Language, and Hearing Research, 48, 1033-1047.

Nation, K., Angell, P., \& Castles, A. (2007). Orthographic learning via self-teaching in children learning to read English: Effects of exposure, durability, and context. Journal of Experimental Child Psychology, 96, 71-84.

National Assessment of Educational Progress. (2007). The nation's report card. Retrieved August 20, 2009, from http://nced.ed.gove/nationsreportcard/reading

Oetting, J., \& McDonald, J. L. (2002). Methods for characterizing participants' nonmainstream dialect use in child language research. Journal of Speech, Language and Hearing Research, 45, 505518.

Pan, B. A., Rowe, M. L., Singer, J. D., \& Snow, C. E. (2005). Maternal correlates of growth in toddler vocabulary production in low-income families. Child Development, 76, 763-782.

Patton-Terry, N., Connor, C., Thomas-Tate, S., \& Love, M. (in press). Examining the relationship between dialect variation, literacy skills, and school context in first grade students. Journal of Speech-Language and Hearing Research.

Qi, C. H., Kaiser, A. P., Milan, S., \& Hancock, T. (2006). Language performance of low-income African American and European preschool children on the PPVT-III. Language, Speech, and Hearing Services in Schools, 37, 5-16.

Reitsma, P. (1983). Printed word learning in beginning readers. Journal of Experimental Child Psychology, 75, 321-339.

Restrepo, M. A., Schwanenflugel, P., Blake, J., Neuharth-Pritchett, S., Cramer, S. E., \& Ruston, H. P. (2006). Performance on the PPVT-III and the EVT: Applicability of the measures with African American and European American preschool children. Language, Speech, and Hearing Services in the Schools, 37, 17-27.

Rice, M., \& Woodsmall, L. (1988). Lessons from television: Children's word learning when viewing. Child Development, 59, 420-429.

Roberts, J. E., Jurgens, J. J., \& Burchinal, M. (2005). The role of home literacy practices in preschool children's language and emergent literacy skills. Journal of Speech, Language, and Hearing Research, 48, 345-359.

Robertson, C., \& Salter, W. (1997). The Phonological Awareness Test. East Moline, IL: Linguisystems.

Rosenthal, J., \& Ehri, L. C. (2008). The mnemonic value of orthography for vocabulary learning. Journal of Educational Psychology, 100, 175-191.

Rosner, J., \& Simon, D. (1971). The Auditory Analysis Test: An initial report. Journal of Learning Disabilities, 4, 40-48.

Scarborough, H. S. (2002). Connecting early language and literacy to later reading (dis)abilities: Evidence, theory, and practice. In S. Neuman \& D. Dickinson (Eds.), Handbook for research in early literacy (pp. 97-110). New York: Guilford Press.

Share, D. L. (1995). Phonological recoding and self-teaching: Sine qua non of reading acquisition. Cognition, 55, 151-218.

Share, D. L. (2004). Orthographic learning at a glance: On the time course and development onset of self-teaching. Journal of Experimental Child Psychology, 87, 267-298.

Siegler, R. S. (1996). Emerging minds: The process of change in children's thinking. New York: Oxford University Press. 
Snow, C. E., Burns, M. S., \& Griffin, P. (Eds.). (1999). Consortium on reading excellence (CORE). Reading research: Anthology: The why? of reading instruction. Novato, CA: Arena Press.

Stephenson, K. A., Parilla, R. K., Georgiou, G. K., \& Kirby, J. R. (2008). Effects of home literacy, parents' beliefs, and children's task-focused behavior on emergent literacy and word reading skills. Scientific Studies of Reading, 12, 24-50.

Storkel, H. L. (2001). Learning new words: Phonotactic probability in language development. Journal of Speech, Language, and Hearing Research, 44, 1321-1337.

Storkel, H. L. (2009). Developmental differences in the effects of phonological, lexical, and semantic variables on word learning in infants. Journal of Child Language, 36, 291-321.

Storkel, H. L., Armbruster, J., \& Hogan, T. P. (2006). Differentiating phonotactic probability and neighborhood density in adult word learning. Journal of Speech, Language, and Hearing Research, 49, 1175-1192.

Storkel, H. L., \& Rodgers, M. A. (2000). The effect of probabilistic phonotactics on lexical acquisition. Clinical Linguistics \& Phonetics, 14, 407-425.

Taylor, D., \& Dorsey-Gaines, C. (1988). Growing up literate: Learning from inner-city families. Portsmouth, NH: Heinemann.

Teale, W. H. (1986). Home background and young children's literacy development. In W. H. Teale \& E. Sulzby (Eds.), Emergent literacy: Writing and reading. Norwood, NJ: Ablex.

Terry, N. P., Connor, C., Thomas-Tate, S., \& Love, M. (2010). Examining relationships among dialect variation, literacy skills, and school context in first grade. Journal of Speech, Language and Hearing Research, 56, 126-145.

Thomas-Tate, S., Washington, J., Craig, H., \& Packard, M. (2006). Performance of African American preschool and kindergarten students on the Expressive Vocabulary Test. Language, Speech and Hearing Services in the Schools, 37, 143-149.

Torgesen, J. K., Wagner, R. K., \& Rashotte, C. A. (1994). Longitudinal studies and phonological processing and reading. Journal of Learning Disabilities, 27, 276-286.

Treiman, R. (1993). Beginning to spell: A study of first-grade children. New York: Oxford University Press.

United States Census Bureau. (2008). Statistical abstract of the United States: 2009 (128th ed.). Washington, DC: Author.

Vernon-Feagans, L., Hammer, C. S., Miccio, A., \& Manlove, E. (2001). Early language and literacy skills in low-income African American and Hispanic children. In S. B. Neuman \& D. K. Dickinson (Eds.), Handbook of early literacy research (pp. 192-210). New York: Guilford Press.

Washington, J. A. (2001). Early literacy skills in African-American children: Research considerations. Learning Disabilities Research and Practice, 16, 213-221.

Washington, J. A., \& Craig, H. K. (1999). Performance of at-risk, African American preschoolers on the Peabody Picture Vocabulary Test-III. Language, Speech, and Hearing Services in the Schools, 30, 75-82.

Wolter, J. A., \& Apel, K. (2010). Initial acquisition of mental graphemic representations in children with language impairment. Journal of Speech, Language, and Hearing Research, 53, 179-195.

Woodcock, R. W. (1998). Woodcock Reading Mastery Tests-Revised. Circle Pines, MN: American Guidance Service.

Wright, D. M., \& Ehri, L. C. (2007). Beginners remember orthography when they learn to read words: The case of doubled letters. Applied Psycholinguistics, 28, 115-133. 